\title{
Brote en simultáneo de Pseudomona aeruginosa y Klebsiella pneumoniae BLEE en una Unidad de Cuidados Intensivos Neonatal de Asunción, Paraguay
}

\author{
*María Esther Pedrozo Torres ${ }^{1}$, Fátima Aidée Vázquez $^{1}$, Nancy Holt ${ }^{2}$, María Águeda Cabello ${ }^{1}$, Margarita \\ Samudio ${ }^{3}$, Deisy Baruja ${ }^{4}$, Dalva De Assis ${ }^{1}$ \\ ${ }^{1}$ Ministerio de Salud Pública y Bienestar Social, Programa de Entrenamiento en Epidemiología de Campo, Dirección \\ General de Vigilancia de la Salud. Asunción-Paraguay \\ ${ }^{2}$ Ministerio de Salud Pública y Bienestar Social. Programa Nacional de Control de Infecciones Intrahospitalarias, \\ Dirección General de Vigilancia de la Salud. Asunción-Paraguay \\ ${ }^{3}$ Universidad Nacional de Asunción, Instituto de Investigaciones en Ciencias de la Salud. San Lorenzo, Paraguay \\ ${ }^{4}$ Ministerio de Salud Pública y Bienestar Social, Hospital Materno Infantil San Pablo. Asunción-Paraguay
}

Cómo referenciar este artículo/ How to reference this article:

\begin{abstract}
Pedrozo Torres ME, Vázquez FA, Holt N, Cabello MA, Samudio M, Baruja D, et al. Brote en simultáneo de Pseudomona aeruginosa y Klebsiella pneumoniae BLEE en una Unidad de Cuidados Intensivos Neonatal de Asunción, Paraguay. Mem. Inst. Investig. Cienc. Salud. 2019; 17(1): 59-68
\end{abstract}

\section{R E S U M E N}

Las Infecciones Asociadas a las Atenciones Sanitarias (IAAS), constituyen un serio problema de salud pública. Se describe un brote de IAAS en una Unidad de Cuidados Intensivos Neonatales de Asunción y las medidas de control implementadas. Estudio descriptivo de serie de casos, entre el 26 de marzo y el 18 de abril del 2013. Fueron utilizados datos secundarios como historias clínicas, registros de enfermería, certificados de defunción, resultados de bacteriología, registros de control de IAAS. El universo estuvo constituido por 12 neonatos, en cuatro se aislaron Pseudomona aeruginosa y en tres Klebsiella pneumoniae BLEE. Predomino el sexo masculino (6/7), la media de edad de 2 días (rango:2-45 días), la mayoría prematuros (5/7). Todos con procedimientos invasivos durante la hospitalización. La tasa global de ataque fue $58 \%(7 / 12)$, con una tasa de ataque para $P$. aeruginosa de $33 \%(4 / 12)$ y para $K$. pneumoniae BLEE de $38 \%(3 / 12)$. La mortalidad global fue $29 \%(2 / 12)$ y la tasa de la letalidad atribuible a la infección por $P$. aeruginosa fue del $50 \%$ (2/4). Las medidas de control del brote fueron el aislamiento de los pacientes infectados, una enfermera por paciente, se intensifico los cuidados de bioseguridad para procedimientos invasivos y lavado de manos; suspensión de pacientes remitidos hasta que se asegurar el corte de transmisión. Se confirmó dos brotes simultáneos con agentes etiológicos diferentes, $P$. aeruginosa y $K$. pneumoniae BLEE. Es necesario reforzar las medidas de control de infecciones y lavado correcto de manos, de manera a prevenir brotes de IAAS en la UCIN.

Palabras clave: brotes, infecciones intrahospitalarias, neonatos, unidad de cuidados intensivos, Pseudomona, Klebsiella, Paraguay

\section{Simultaneous outbreak of Pseudomonas Aeruginosa and ESBL producing-Klebsiella Pneumoniae in a Neonatal Intensive Care Unit of Asunción, Paraguay}

\footnotetext{
A B S T R A C T

Health care-associated infections (HCAI) constitute a serious public health problem. We describe an outbreak of HCAI in a Neonatal Intensive Care Unit (NUCI) in Asunción and the implemented control measures. This was a descriptive observational study of case series,
} 
performed between March 26th and April 18th, 2013. It is based on secondary data of the NICU, such as medical charts, nursing registries, death certificates, laboratory results and infection control registry forms. The study population consisted of 12 neonates. Pseudomona aeruginosa was isolated from biological samples of four neonates while ESBL producing-Klebsiella pneumoniae was isolated from other three patients. The patients were predominantly male (6/7), the average age was 2 days (range: 2-45 days), mostly premature babies (5/7). Invasive procedures were present in all cases. The overall attack rate was $58 \%(7 / 12)$, with an attack rate for $P$. aeruginosa of $33 \%(4 / 12)$ and for ESBL producing-K. Pneumoniae of 38\% (3/12). Overall mortality was 29\% (2/12) and the lethality rate attributable to $P$. aeruginosa infection was $50 \%(2 / 4)$. Measures implemented to control the outbreak were isolation of infected patients, one nurse per patient, intensified biosafety of invasive procedures strict control on proper hand washing, and interruption of patient transfers from other hospital during the outbreak. There were two simultaneous outbreaks with two different ethological agents, $P$. aeruginosa and ESBL producing-K. Pneumoniae. It is necessary to reinforce infection control measures and correct hand washing, in order to prevent outbreaks of HCAI in the NICU.

Keywords: outbreak, nosocomial infections, newborns, intensive care units, Pseudomonas, Klebsiella, Paraguay

\section{INTRODUCCIÓN}

Una Infección Asociada a la Atención Sanitaria (IAAS), se define como que aquella que no está presente ni incubándose en el momento de la admisión, pero que se observa durante la estadía hospitalaria o alta al paciente ${ }^{(1)}$. Según informe de la Organización Mundial de la Salud (OMS), se calcula que a nivel mundial cientos millones de pacientes por año se ven afectados por IAAS, constituyendo así un serio problema de salud pública, ya sea por el difícil manejo de los pacientes debido a que muchos de los microorganismos implicados son resistentes a varios antibióticos; el alto costo para los sistemas de salud y las pérdidas económicas para los pacientes y sus familiares, al mismo tiempo de causar muertes innecesarias en muchos $\operatorname{casos}^{(2)}$.

La OMS refiere que, en el 2013, se reportaron 2,8 millones de muertes neonatales, de los cuales 0,43 millones (rango de incertidumbre: 0,22-0,66) fueron por sepsis y otras infecciones graves, causando casi la mitad las muertes neonatales tardías (desde los 7 a los 27 días de vida) ${ }^{(3)}$. Estudios realizados en Latinoamérica, refieren que las incidencias de IAAS en las Unidades de Cuidados Intensivos Neonatales (UCIN) tienen un margen de 7,1 $\%$ a $41 \%{ }^{(4-6)}$. Y que entre los factores predisponentes inherentes del neonato para adquirir una IAAS se encuentran el bajo peso al nacer y la corta edad gestacional, además de factores externos como la estancia hospitalaria prolongada, la utilización de dispositivos invasivos y el hacinamiento de cunas entre otros ${ }^{(7)}$.

Entre las bacterias más comúnmente aisladas en IAAS de neonatos se encuentran las bacterias Gram positivas como: Staphylococcus aureus (40\%), Streptococcus Grupo A (infección cruzada por el personal del hospital) y las bacterias Gram negativas como: Escherichia coli, Klebsiella, Enterobacter, Proteus y las Pseudomona aeruginosa ( $P$. aeruginosa) ${ }^{(4,8,9)}$. Cabe destacar que la $P$. aeruginosa se caracteriza por un alto grado de adaptabilidad fisiológica y elevados niveles de resistencia frente a numerosos agentes antimicrobianos, con lo cual se constituye como uno de los patógenos nosocomiales más frecuentes, con una elevada morbilidad y mortalidad ${ }^{(4,8-9)}$.

Se ha demostrado que la ruptura del cumplimiento de las normas de control de infecciones puede dar origen a un brote en un servicio hospitalario. Un brote es definido como la aparición de dos o más casos de IAAS en el lapso de 15 días, o un aumento de IAAS por encima de los niveles endémicos o históricos del servicio para determinado microorganismo ${ }^{(10)}$. Según el tipo de transmisión se clasifican: brote por fuente común, si se presenta como un aumento rápido de la tasa de infección muchas veces por un único germen; Brote por transmisión de persona a persona, si aparecen casos más esporádicos y generalmente está relacionado a la falta de lavado de manos o equipamiento contaminado. Además de brotes por microorganismos diferentes, que habitualmente se debe a una brecha en el cumplimiento de las normas de control de infecciones ${ }^{(10)}$.

En Paraguay, si bien se cuentan con publicaciones de brotes de IAAS, no se ha encontrado datos de incidencia de IAAS en las UCIN. Y debido a que los estudios de brotes aportan información epidemiológica que apoyan a establecer medidas de control y proponer 
recomendaciones para evitar eventos futuros ${ }^{(1)}$, se considera de relevancia describir el estudio de un brote de IAAS que afecto a una UCIN de Asunción, que fue investigado en el marco del Programa de Entrenamiento en Epidemiologia de Campo de Paraguay.

\section{MATERIALES Y MÉTODOS}

Se realizó un estudio observacional descriptivo de serie de casos, entre el 26 de marzo y el 18 de abril del 2013, en una UCIN de un Hospital Materno Infantil de Asunción. La UCIN con capacidad para 12 neonatos, es considerada una terapia "abierta", en las cual los neonatos pueden estar acompañados por sus padres durante la mayor parte de su hospitalización, previo lavado correcto de las manos, para lo cual disponen de una pileta para lavado de manos con solución antiséptica y papel absorbente. En el protocolo para ingreso de pacientes remitidos de otras instituciones, se incluyen la realización de hemocultivos y cultivos de hisopados anales, además de iniciar un tratamiento antimicrobiano empírico, el cual puede ser modificado o descartado según resultados de microbiología. El promedio de egresos en el año anterior fue de 50 pacientes/mes.

Fuente de datos. Se revisaron los registros de control de infecciones, las historias clínicas, los resultados de microbiología, los certificados de defunción, los registros de traspaso de guardia de los profesionales de salud antes y durante el evento. Para conocer el histórico de IAAS se verificaron los registros hospitalarios del año anterior. Una vez seleccionados los expedientes, se aplicó un instrumento de recolección de datos que incluyo datos demográficos, características del neonato y las posibles exposiciones en la UCIN, signos y síntomas de IAAS, procedimientos invasores y antibioterapia.

Búsqueda activa hospitalaria. Para la identificación de casos se establecieron las siguientes definiciones:

Caso sospechoso "todo neonato hospitalizado en la UCIN del hospital materno infantil de Asunción entre el 26/03/13 y 18/04/18, y que luego de 48 horas o más de internación haya presentado fiebre $\left(>38^{\circ} \mathrm{C}\right)$ con uno o más de los siguientes signos o síntomas: hipotermia $\left(<37^{\circ} \mathrm{C}\right)$, apnea, dificultad respiratoria, piel reticulada o aumento de secreción traqueal"; y como Caso confirmado "todo caso sospechoso en cuyo resultado de laboratorio se aísle algún microorganismo".

Los casos confirmados se clasificaron según localización ${ }^{(1)}$ en:

Neumonía: si el caso sospechoso presentó fiebre $\left(>38^{\circ} \mathrm{C}\right)$ sin otra causa conocida acompañada de aumento de secreciones respiratorias o mayor requerimiento de aspiración, o nueva aparición o empeoramiento de tos, disnea o taquipnea.

Bacteriemia: si el caso sospechoso presento al menos uno de los siguientes signos o síntomas sin otra causa aparente: fiebre $\left(>38^{\circ} \mathrm{C}\right)$, hipotermia, apnea, bradicardia con resultados de laboratorio positivos que no se relacionan en otra localización.

Sepsis: caso sospechoso con hemocultivo sin crecimiento y sin infección aparente en otro sitio y con tratamiento para sepsis.

Además, se realizaron entrevistas semiestructuradas a profesionales actuantes del área sobre las medidas de control utilizados antes y durante el evento.

Para la búsqueda microbiológica de posibles fuentes de infección, se tomaron muestras de antisépticos en uso y agua que se acumulaban en las conexiones de los respiradores. La obtención de muestras se realizó por profesionales del laboratorio.

Análisis de datos. Se elaboró una base de datos con el software informático Excel, y los cálculos se realizaron con el software informático Epi Info 7.1. Se utilizaron medidas estadísticas de tendencia central y dispersión para las variables cuantitativas, número absoluto, tasas y porcentaje para las variables cualitativas. Se calcularon las tasas de ataque y las tasas de IAAS en dos periodos de tiempo preestablecidos (endémico y epidémico). Fue considerado como período epidémico el tiempo trascurrido entre la aparición del primer y el último caso; y como periodo endémico seis meses antes de la aparición del primer caso. Como numerador se utilizó el número de casos en cada período y como denominadores fueron considerados el número de ingresos y el número de egresos respectivamente ${ }^{(11)}$.

\begin{tabular}{|c|c|}
\hline \multirow{2}{*}{ Tasa de IAAS (período epidémico*) = } & $\mathrm{N}^{\circ}$ casos infectados $\times 100$ \\
\hline & $\mathrm{N}^{\circ}$ de ingresos $*$ \\
\hline Tasa de IAAS (per & $\mathrm{N}^{\circ}$ casos infectados $\times 100$ \\
\hline
\end{tabular}


*Corresponde al periodo en que se identificó el primer caso y el último caso.

Se calculó con $\mathrm{N}^{\circ}$ de ingresos para evitar sesgo y porque los registros de egresos se realizan de manera mensual.

**Corresponde a seis meses antes del comienzo del evento. Con el histórico del servicio para un mismo microorganismo.

Cuestiones éticas. Se solicitó autorización a directivos del hospital para recabar datos de las historias clínicas de los pacientes. Los datos obtenidos, así como toda la información de esta investigación fueron manejados en forma confidencial y utilizada exclusivamente para el cumplimiento de objetivo propuesto.

\section{RESULTADOS}

\section{Descripción del brote}

El universo estuvo constituido por 12 neonatos, de los cuales ocho fueron identificados como sospechosos. El caso primario inició síntomas el 26 de marzo de 2013, tras 45 días de internación en la UCIN, y entre el 02 y el 09 de abril iniciaron síntomas siete casos más. De los cuales, en cuatro casos se aislaron P. aeruginosa (en tres neumonías y una bacteriemia) y tres casos con Klebsiella pneumoniae Beta Lactamasa de Espectro Extendido (BLEE) (en una neumonía y dos bacteriemias). En un caso no se aisló ninguna bacteria y fue clasificado como sepsis. La distribución temporal de los casos según fecha de inicio de síntomas, que señala una trasmisión del tipo propagada (Figura 1).

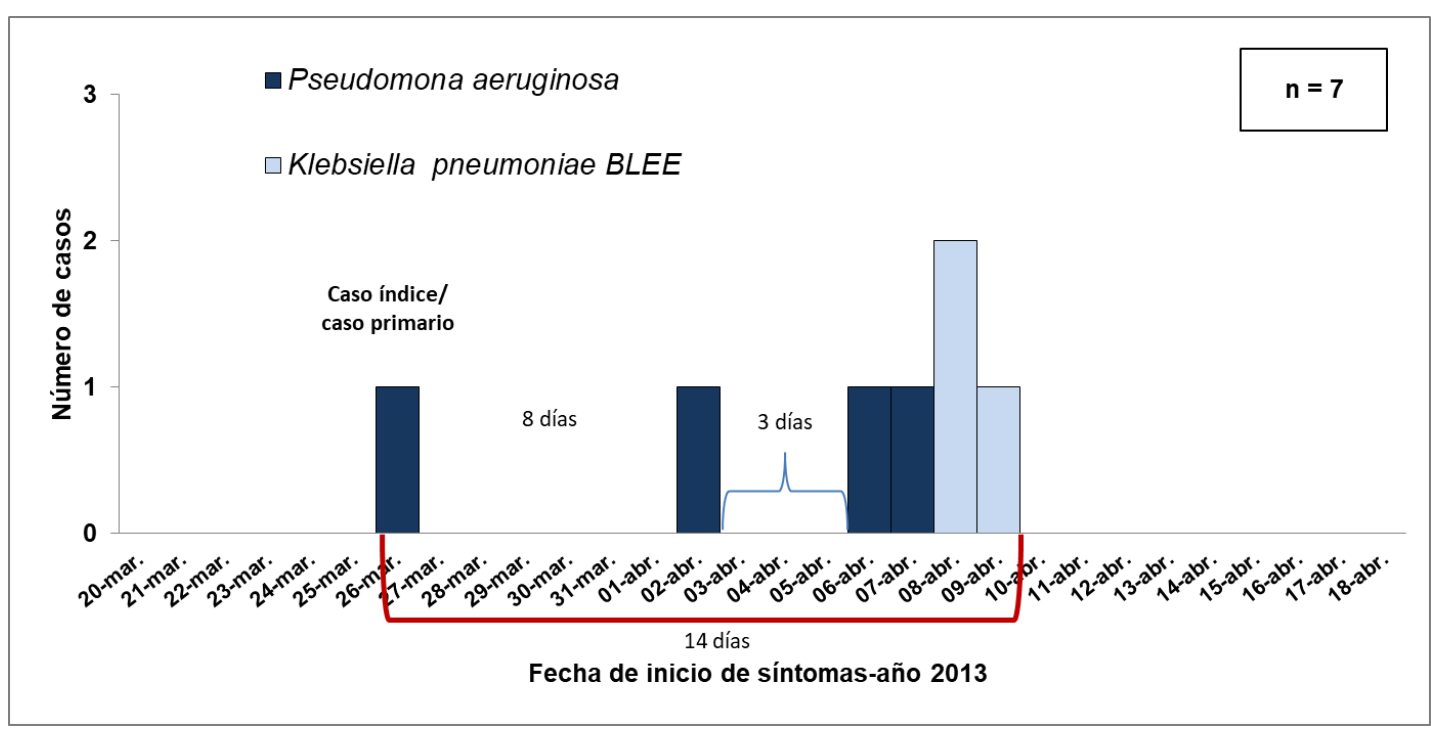

Fuente: Pedrozo E., Vázquez F., Holt N., Cabello A., Samudio M., Baruja D., Assis D. Brote en simultáneo de Pseudomona aeruginosa y Klebsiella pneumoniae BLEE en una Unidad de Cuidados Intensivos Neonatal de un Hospital de Asunción, Paraguay

Figura 1. Curva epidémica de neonatos con IAAS en una UCIN de Asunción, Paraguay

En la Figura 2, se observa la distribución de días de internación antes y durante el inicio de síntomas. Todos los casos estuvieron temporalmente relacionados entre sí, y dos evolucionaron al óbito. 


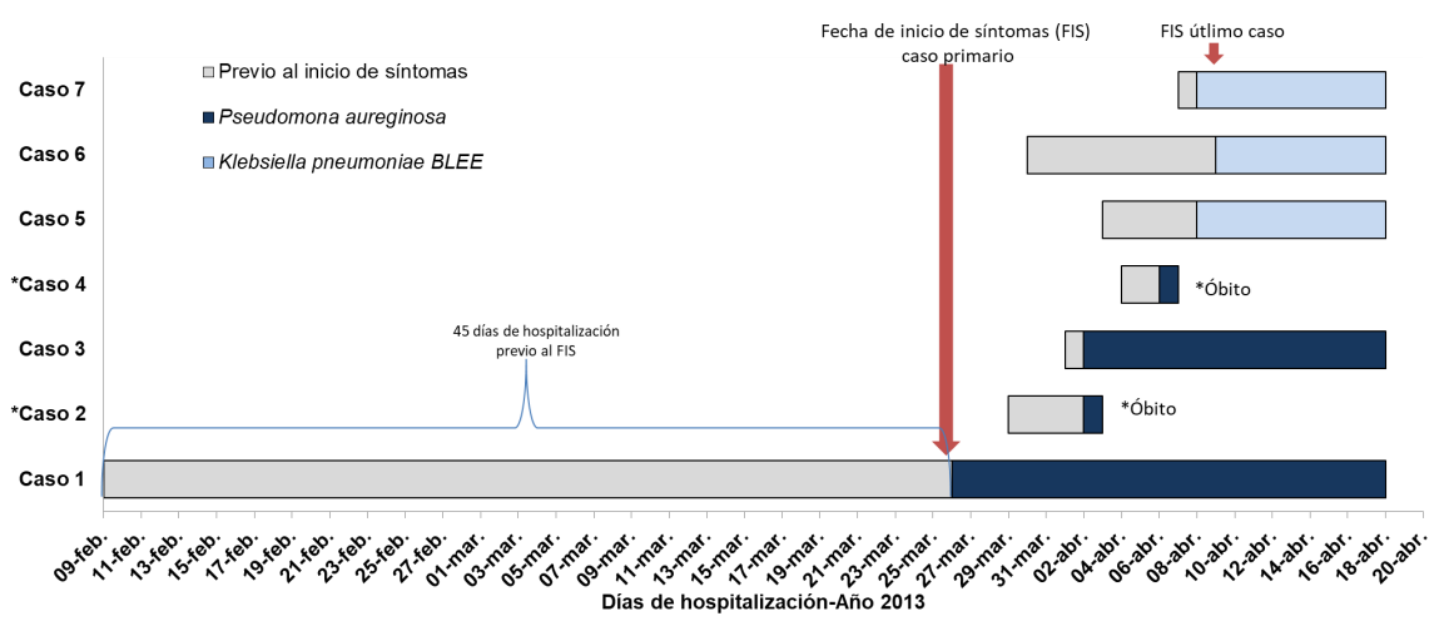

Fuente: Pedrozo E., Vázquez F., Holt N., Cabello A., Samudio M., Baruja D., Assis D. Brote en simultáneo de Pseudomona aeruginosa y Klebsiella pneumoniae BLEE en una Unidad de Cuidados Intensivos Neonatal de un Hospital de Asunción, Paraguay

Figura 2. Línea de tiempo de neonatos con IAAS en relación de los días de hospitalización en una UCIN y la aparición de síntomas, Asunción-Paraguay.

\section{Caracterización de los casos}

En los casos confirmados predomino el sexo masculino (6/7), con una media de edad desde el nacimiento al inicio de síntomas de 12 días (rango: 2 a 45 días), la mayoría fueron prematuros y parto por cesárea (5/7). Todos con hemocultivo de ingreso negativo y con procedimientos invasivos durante la hospitalización (Tabla 1 ).

Tabla 1. Características demográficas de casos con IAAS en una UCIN de Asunción, Paraguay.

\begin{tabular}{lrr} 
& & $\mathbf{N}=\mathbf{7}$ \\
\hline Características & $\mathbf{n}$ & $\%$ \\
\hline Sexo masculino & 6 & 86 \\
Edad en días (mediana, rango) & 8 & $(2-45)$ \\
Edad gestacional en semanas (mediana, rango) $^{*}$ & 38 & $(29-41)$ \\
Neonatos prematuros $^{*}$ & 4 & 57 \\
Bajo peso al nacer $^{* *}$ & 3 & 43 \\
Parto por cesarea $_{\text {Referidos de otra institución }}$ & 5 & 71 \\
Hemolcultivo de ingreso negativo & 5 & 71 \\
Procedimientos invasivos & 7 & 100 \\
\hline
\end{tabular}

* Prematuros (según OMS) = nacimientos $<37$ Semanas de gestación

**Bajo peso al nacer (según OMS): < 2500 gramos al nacimiento

En cuanto a los diagnósticos de ingreso más frecuentes se encontraron el síndrome de aspiración de líquido meconial (5/7), síndrome de distrés respiratorio (4/7), asfixia perinatal (3/7) y la hipertensión pulmonar (3/7). Los signos y síntomas más frecuentes fueron la fiebre (7/7) y el aumento de secreción endotraqueal (2/7). Todos los casos fueron infecciones, no se detectaron colonizaciones. Las localizaciones de las infecciones fueron cuatro neumonías y tres bacteriemias asociadas a catéter venoso central. De los casos con $P$. aeruginosa y Klebsiella pneumoniae BLEE detectados, se aislaron otras bacterias más (tres en secreción traqueal y una en punta de catéter). En cuanto al tratamiento antimicrobiano, seis casos fueron tratados con ceftazidima y vancomicina. Dos casos con $P$. aeruginosa evolucionaron al óbito y los demás evolucionaron favorablemente (Tabla 2). 
Tabla 2. Características de casos con infección intrahospitalaria en una unidad de cuidado intensivo neonatal de un Hospital materno infantil de Asunción, Paraguay; abril-2013

\begin{tabular}{|c|c|c|c|c|c|c|c|}
\hline $\mathbf{N}^{\circ}$ & $\begin{array}{l}\text { Edad } \\
\text { (días) }\end{array}$ & FIS* & Signos & Tipo de material & Microbiología & Tratamiento & Evolución \\
\hline Caso 1 & 45 & $\begin{array}{l}05-a b r \\
08-a b r\end{array}$ & $\begin{array}{l}\text { Aumento de } \sec ^{* *} \text {. } \\
\text { traqueal } \\
\text { Distermia } \\
\text { Fiebre } \\
\text { Aumento de sec. } \\
\text { traqueal }\end{array}$ & $\begin{array}{l}\text { Sec. traqueal } \\
\text { Hemocultivo } \\
\text { Hemocultivo } \\
\text { Sec. traqueal }\end{array}$ & $\begin{array}{l}\text { P. aeruginosa, } \\
\text { S. aerus } \\
\text { No se aísla bacterias } \\
\text { No se aísla bacterias } \\
\text { P. aeruginosa } \\
\text { S. malophilia }\end{array}$ & $\begin{array}{l}\text { Ceftazidima, } \\
\text { vancomicina }\end{array}$ & Internado \\
\hline Caso 2 & 3 & $02-a b r$ & $\begin{array}{l}\text { Fiebre } \\
\text { Piel reticulada }\end{array}$ & $\begin{array}{l}\text { Secreción traqueal } \\
\text { Hemocultivo }\end{array}$ & $\begin{array}{l}\text { P. aeruginosa } \\
\text { P. aeruginosa }\end{array}$ & $\begin{array}{l}\text { Ceftazidima } \\
\text { Vancomicina }\end{array}$ & Óbito \\
\hline Caso 3 & 16 & $02-a b r$ & $\begin{array}{l}\text { Aumento de sec. } \\
\text { traqueal } \\
\text { Fiebre }\end{array}$ & $\begin{array}{l}\text { Sec. traqueal } \\
\text { Hemocultivo }\end{array}$ & $\begin{array}{l}\text { P. aeruginosa } \\
\text { E. clocae } \\
\text { P. aeruginosa }\end{array}$ & Meropenen & Internado \\
\hline Caso 4 & 4 & $07-a b r$ & Fiebre & $\begin{array}{l}\text { Hemocultivo } \\
\text { Retrocultivo }\end{array}$ & $\begin{array}{l}P \text {. aeruginosa } \\
P \text {. aeruginosa }\end{array}$ & $\begin{array}{l}\text { Ceftazidima } \\
\text { Vancomicina }\end{array}$ & Óbito \\
\hline Caso 5 & 5 & $08-a b r$ & $\begin{array}{l}\text { Temperatura } \\
\text { inestable, } \\
\text { hipotenso, oligurico, } \\
\text { mucosa seca con } \\
\text { sangrado } \\
\text { endotraqueal }\end{array}$ & $\begin{array}{l}\text { Punta de catéter } \\
\text { Hemocultivo }\end{array}$ & $\begin{array}{l}\text { S. coagulasa } \\
\text { negativo } \\
\text { K. pneumoniae BLEE }\end{array}$ & $\begin{array}{l}\text { Ceftazidima, } \\
\text { vancomicina, } \\
\text { amicacina } \\
\text { Meropenen, } \\
\text { vancomicina, } \\
\text { amicacina }\end{array}$ & Internado \\
\hline Caso 6 & 10 & $09-a b r$ & Fiebre & $\begin{array}{l}\text { Hemocultivo } \\
\text { Retrocultivo }\end{array}$ & $\begin{array}{l}\text { K. pneumoniae BLEE } \\
\text { K. pneumoniae BLEE }\end{array}$ & $\begin{array}{l}\text { Ceftazidima } \\
\text { Vancomicina }\end{array}$ & Internado \\
\hline Caso 7 & 2 & $08-a b r$ & Fiebre & $\begin{array}{l}\text { Sec. traqueal } \\
\text { Hemocultivo }\end{array}$ & $\begin{array}{l}\text { K. pneumoniae BLEE } \\
\text { No se aísla bacterias }\end{array}$ & $\begin{array}{l}\text { Ceftazidima, } \\
\text { vancomicina, } \\
\text { meropenen }\end{array}$ & Internado \\
\hline
\end{tabular}

Fuente: Pedrozo E., Vázquez F., Holt N., Cabello A., Samudio M., Baruja D., Assis D. Brote en simultáneo de Pseudomona aeruginosa y Klebsiella pneumoniae BLEE en una Unidad de Cuidados Intensivos Neonatal de un Hospital de Asunción, Paraguay

\section{Histórico del servicio}

Las tasas de IAAS del servicio en el periodo epidémico y en el periodo endémico (comportamiento histórico) para $P$. aeruginosa fueron de $6,9 \%$ y $1,4 \%$; y para la $K$. pneumoniae BLEE fueron $5,2 \%$ y $1,1 \%$ respectivamente. La tasa global de ataque fue del $58 \%(7 / 12)$, con una tasa de ataque para $P$. aeruginosa de $33 \%(4 / 12)$, y una tasa de ataque para $K$. pneumoniae BLEE de $38 \%$ (3/12). La mortalidad global fue $29 \%(2 / 12)$ y la tasa de la letalidad atribuible a la infección por $P$. aeruginosa fue del $50 \%(2 / 4)$.

Comparando el histórico del año anterior con respecto al 2013, no se observó aumento en cuanto al número de óbitos. Sin embargo, al comparar el patrón de circulación bacteriana en el mismo periodo de tiempo (enero-abril), se observó que el 2012 también se registró un aumento de casos, pero con predominio de bacterias Gram positivas, determinado por un brote de $S$. coagulasa negativo con corte de trasmisión en julio (Figura $3)$. 


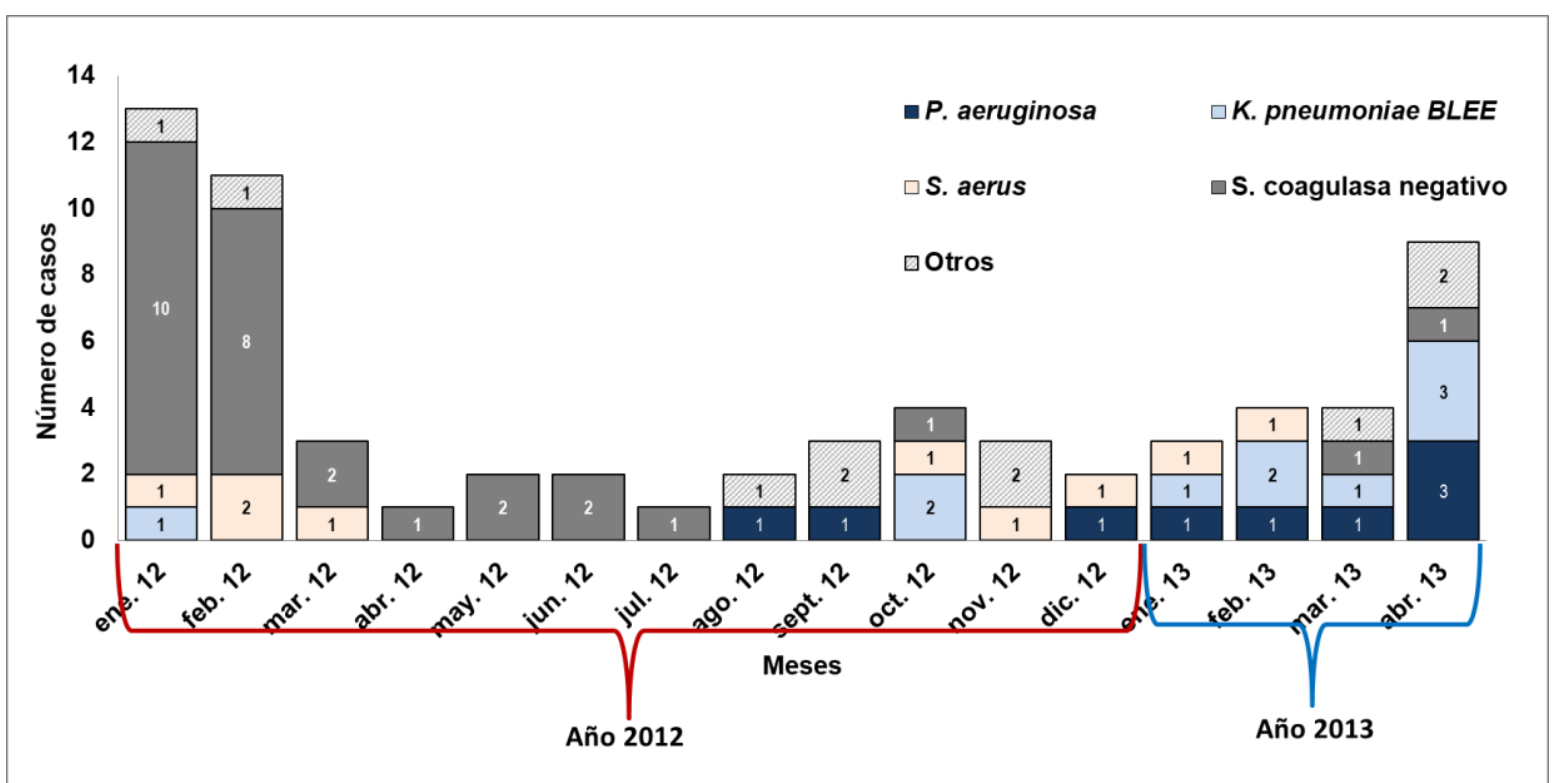

Figura 3. Distribución de bacterias aisladas por mes de los años 2012-2013 en una UCIN de Asunción-Paraguay

Fuente: Pedrozo E., Vázquez F., Holt N., Cabello A., Samudio M., Baruja D., Assis D. Brote en simultáneo de Pseudomona aeruginosa y Klebsiella pneumoniae BLEE en una Unidad de Cuidados Intensivos Neonatal de un Hospital de Asunción, Paraguay

\section{Estudio ambiental}

En la búsqueda microbiológica de posibles fuentes de infección, en cuatro muestras de antisépticos en uso y tres muestras de agua acumulada en las conexiones de los respiradores de los tres primeros casos, no se aislaron bacterias.

\section{Prácticas de bioseguridad previo al evento}

Al indagar la secuencia sobre las prácticas de bioseguridad realizadas por el personal de salud previo al inicio del brote se describieron algunas irregularidades, tales como: personal de enfermería disminuido (incluyendo el ingreso de personal nuevo al servicio y de enfermeras pasantes de otra institución); por disminución de insumos, el personal utilizaba un solo rollo de toallas de papel sin dispensadores por mesada para secarse las manos y en algunas ocasiones incluso se utilizaban toallas de tela. Además, las soluciones antisépticas eran fraccionadas en frascos para cada lavamanos de forma diaria eliminando los residuos, posterior lavado del frasco con detergente y con un recargado inmediato.

Se constató, que los recursos en el laboratorio de microbiología eran insuficientes, tenían un profesional bioquímico y un técnico de laboratorio, que realizan los cultivos, de manera tradicional ya que no cuentan con equipos automatizados para hemocultivo.

\section{Medidas de control del brote}

Al percatarse de un aumento de IAAS el Comité de Control de Infecciones Intrahospitalaria recomendó intensificar el control de infecciones, así como el lavado correcto de las manos, se extremaron las medidas de bioseguridad para procedimientos invasivos; se separaron los casos confirmados en cohorte y se designó enfermeras exclusivas para el cuidado de los casos con IAAS, además de suspender el ingreso de pacientes remitidos de otras instituciones hasta asegurar el corte de trasmisión.

Se verificó la aparición de nuevos casos hasta el 30 de abril de 2013 (20 días luego de la fecha de inicio de síntomas del último caso), no registrándose ningún caso nuevo.

\section{DISCUSIÓN}

Se confirmó la existencia de dos brotes de IAAS relacionados entre sí, con diferentes agentes etiológicos: $P$. aeruginosa y $K$. pneumoniae BLEE, basados en los aspectos espacio temporales, las tasas de infección nosocomial en periodo epidémico superiores a los del periodo endémico según comportamiento histórico del servicio para cada una de las bacterias, con una transmisión del tipo propagada.

La tasa de ataque global encontrada en este estudio fue ligeramente superior a las reportadas en la literatura que van del $7 \%$ al $41 \%$ para todos los agentes comúnmente observados en este mismo ambiente ${ }^{(4-6,8)}$. En este estudio predominaron las bacterias Gram negativas, característica semejante a otros estudios en neonatos ${ }^{(9,12)}$. En cuanto a las 
localizaciones de las IAAS, se encuentran diferencias en cuanto a los patrones históricos según los servicios; por ejemplo, en un estudio realizado por Herrera en una UCIN en Bogotá-Colombia predominaron las bacteriemias asociada a catéter venoso en un 34,4\%, infecciones del tracto urinario $24,9 \%$ y neumonías en un $12,2 \%{ }^{(13)}$. En tanto que, en el estudio realizado por Sampedro en una UCIN de Ecuador, se encontró que las neumonías representaban el $38 \%$ de las IAAS, y las sepsis/bacteriemias un $32,6 \%{ }^{(6)}$, este último patrón fue coincidente con esta investigación.

Según la literatura, la mortalidad estimada por IAAS en neonatos es de 4 a $13 \%$; en tanto que, para $P$. aeruginosa que se caracteriza por una alta morbilidad y mortalidad, oscila entre $18 \%$ a $61 \%,{ }^{(14-16)}$. No obstante, en este estudio la mortalidad global en el periodo epidémico fue elevada, debido a la alta letalidad en los casos con $P$. aeruginosa. En cuanto a los factores predisponentes para adquirir una IAAS, un estudio realizado por Arias concluye que los neonatos con bajo peso al nacer ( $<1000$ gramos), tienen mayor riesgo de adquirir una IAAS que los que nacen con peso adecuado ( $>2500$ gramos); así como los neonatos con hospitalización prolongada ( $>28$ días) ${ }^{(17)}$. En este brote se encontraron factores predisponentes similares a otros estudios, tales como predominio del sexo masculino, condiciones como bajo peso al nacer, pre término, parto por cesárea, procedimientos invasivos y hospitalización prolongada entre otros ${ }^{(12,18-20)}$.

En cuanto al tratamiento empírico con antibioterapias se ha encontrado estudios que refieren que en las UCIN al menos el $75 \%$ de todos los neonatos reciben antibioterapias a las 48 horas de hospitalización ${ }^{(21)}$. En contraste, otros estudios recomiendan que se debe evitar el tratamiento empírico de manera a evitar la aparición de multirresistencias. Ante esta discrepancia de criterios, en este estudio resultó fundamental el tratamiento empírico por las características inherentes de la $P$. aeruginosa en cuanto a un peor pronóstico si hay un retraso en el inicio del tratamiento, además de ser clínicamente indistinguible de otras afecciones por bacilos Gram negativos, sumado a que en dicho servicio de salud no se cuenta con diagnostico microbiológico en tiempo oportuno, debido a la falta de automatización y de recursos humanos insuficiente dentro del laboratorio de microbiología.

En la literatura también se ha referido que los factores extrínsecos asociados para la adquisición de IAAS son el desarrollo físico, la relación entre el número de enfermeras y los pacientes y el equipo ${ }^{(21)}$. Cabe destacar que en el primer trimestre del 2012 también se registró un brote de IAAS en el mismo servicio, con situaciones similares a las encontradas en el periodo del brote, tales como rotación de personal de guardia, permisos por vacaciones y reposos médicos, lo que conllevó a un aumento de la relación paciente/enfermera ( 3 a 4/enfermera), por lo que se presume que esta situación pudo haber sido un factor predisponente primordial para la aparición de las IAAS en ambos años.

Así también en un meta-análisis realizado por Oliveira y colaboradores, refiere que las IAAS principales en la UCIN se producen por transmisión cruzada de microorganismos de la mano de profesionales de la salud, de las superficies ambientales, equipos y elementos no críticos contaminados ${ }^{(22)}$. En este estudio de brote, como ya se mencionó anteriormente presento una transmisión propagada, característico de una contaminación exógena; además del hecho que se cortará la trasmisión implementando medidas de control más estrictas, sugiere y refuerza los estudios realizados anteriormente que el lavado de manos y el uso adecuado de soluciones antisépticas y toallas reduce el riesgo de infección ${ }^{(23-26)}$.

Es sumamente importante la función del Comité de Control de IAAS hospitalario, ya que es el encargado de establecer un sistema de vigilancia eficiente para determinar las incidencias y las características de las mismas, así como definir los mecanismos de control necesarios en tiempo oportuno, y así evitar la diseminación de paciente a paciente.

Entre las limitaciones de este estudio, se mencionan fue no se logró identificar la fuente de infección debido a que la investigación incluyendo los análisis microbiológicos del ambiente se realizaron luego de la implementación de las medidas de control más estrictas, además de no contar con herramientas moleculares para la investigación de este brote.

En conclusión, se confirmó la existencia de dos brotes de IAAS con diferentes agentes etiológicos: $P$. aeruginosa y $K$. pneumoniae BLEE; con corte de trasmisión luego de la implementación de medidas de control más estrictas, lo que sugiere una brecha en el cumplimiento de las normas de control de infecciones previo al brote. Por tanto, se recomienda establecer actividades periódicas de capacitación y motivación a todo el personal (principalmente al de nuevo ingreso) sobre la importancia de las normas de prevención de IAAS, recalcando el cumplimiento estricto de técnicas asépticas; al mismo 
tiempo de garantizar los recursos necesarios al servicio (ropas, toallas de papel, recipientes individuales para soluciones antisépticas); con la utilización de material de diagnóstico limpio y estéril, así como fortalecer el área de bacteriología e implementar el control periódico de esterilidad con cultivos ambientales y de equipos estériles del servicio.

CONFLICTO DE INTERESES: Los autores declaran no tener conflicto de intereses.

\section{AGRADECIMIENTOS}

Por su valiosa colaboración a las Dra. Ana Arrechea, Lic. Rosa Núñez, Dra. Lariza Genez, Lic. Aidee Bogado, Dra. Antonia Gurrieli y Dra. Liza Paredes del HMISP-MSPBS.

\section{REFERENCIAS BIBLIOGRÁFICAS}

1. Paraguay. Ministerio de Salud Pública y Bienestar Social. Dirección General de Vigilancia de la Salud. Manual de Vigilancia de Infecciones Asociadas a Atenciones Sanitarias. Asunción, 2017.

2. Organización Mundial de la Salud. Carga mundial de infecciones asociadas a la atención sanitaria (Internet). WHO. (citado 20 de noviembre de 2014). URL disponible en:

http://www.who.int/gpsc/country_work/bu rden_hcai/es/

3. Oza S, Lawn J, Hogan D, Colin Mathersb C, Cousensa S. Neonatal cause-of-death estimates for the early and late neonatal periods for 194 countries: 2000-2013 (En línea). Bull World Health Organ. 2015. (citado el 20 de noviembre de 2018). 93:19-28. URL disponible en: doi: 10.2471/BLT.14.139790

4. Useche J, Numez E, Torres H. Brote por Klebsiella pneumoniae multirressitente $y$ productora de B-lactamasa de espectro extendido en una unidad de alto riesgo neonatal. Salus revista de la Facultad de Ciencias de la Salud- Universidad de Carabobo (En línea). 2012 (citado el 20 de noviembre de 2018). 16 (3): 33-9. URL disponible en: http://servicio.bc.uc.edu.ve/fcs/index.htm

5. García H, Torres J, Peregrino L, Cruz M. Factores de riesgo asociados a infección nosocomial (IN) en una Unidad de Cuidados Intensivos Neonatales (UCIN) de tercer nivel. Gac Med Mex. (En línea) 2015. (citado el 10 de noviembre de 2018) 151:711-9. URL disponible en: https://www.anmm.org.mx/GMM/2015/n6/ GMM_151_2015_6_711-719.pdf

6. Sampedro Chica NL. Prevalencia de infecciones asociadas a la atención de salud en la Unidad de Cuidados Intensivos Neonatales. (Tesis). 2018 (citado el 5 de diciembre de 2018). Ecuador: Repositorio de Institucional de la Universidad de Guayaquil. URL disponible en: http://repositorio.ug.edu.ec/handle/redug/ 31241

7. González C, Gil F, Solórzano M, Cruz J, Puig J, Suárez M et al. Brote por Klebsiella pneumoniae multiresistentes y productora de $\beta$-Lactamasa de espectro extendido en

una unidad de alto riesgo neonatal. Rev Chil Infectol (En línea). 2011. (citado 15 abril 2013); 28(1):28-34. URL Disponible en:

http://www.scielo.cl/scielo.php?script $=$ sci_ arttext\&pid $=$ S0716$10182011000100005 \&$ Ing $=$ es. http://dx.doi.org/10.4067/S071610182011000100005.

8. Abramczyk ML, Carvalho WB, Carvalho ES, Medeiros EAS. Nosocomial infection in a pediatric intensive care unit in a developing country. Braz J Infect Dis. [En línea] 2003; (citado 17 de marzo de 2015). 7(6):37580. URL disponible en: http://www.scielo.br/scielo.php?pid=S141 3-

86702003000600004\&script $=$ sci_arttext:

9. Turrini RNT. Nosocomial infection and mortality. Rev Esc Enferm USP. [En línea] 2002. (citado 17 de marzo de 2015). 36(2):177-83. URL disponible en: http://www.scielo.br/pdf/reeusp/v36n2/v3 6n2a10.pdf

10. Sarubbi M. Prevención de infecciones hospitalarias en las unidades de cuidado intensivo neonatal (UCIN). Revista del Hospital Materno Infantil Ramón Sardá. Buenos Aires. 2005. 24(4):148-56.

11. Ávila JL. Método práctico para el diagnóstico y control de un brote de infección intrahospitalaria en un servicio de neonatología. Rev Cubana Salud Pública [En línea]. 2011. (citado el 24 de mayo de 2016). 37(4):442-451. URL disponible en: http://scielo.sld.cu/scielo.php?script=sci_a rttext\&pid $=$ S086434662011000400008\&lng=es.

12. Hing $L$, Poutou $E$, Venezuela $C$, Urge-Ihes G, Aguilar G, Ramírez G. Factores de riesgo de la sepsis neonatal (En línea). 2006 (citado 21 de noviembre de 2014). 10(04):406-19. URL disponible en: http://webcache.googleusercontent.com/se arch?q=cache:FPANkXFZKuYJ:bvs.sld.cu/r evistas/san/vol10_04_06/san04406.pdf+\& $\mathrm{cd}=2 \& \mathrm{hl}=\mathrm{es}-419 \& \mathrm{ct}=\mathrm{c}$ lnk \&gl=py

13. Herrera J. Caracterización de los pacientes con Infección Asociada a la Atención en la Salud (IAAS) en los servicios de cuidado intensivo y cuidado intermedio neonatal de la fundación HOMI 
Hospital de La Misericordia de Bogotá (Tesis) Colombia: Universidad Nacional de Colombia - Sede Bogotá. 2018 (citado 28 de diciembre de 2018). URL disponible en: http://bdigital.unal.edu.co/63874/2/79916 094.2018.pdf

14. Richards M, Edwards J, Culver D, Gaynes $R$. Nosocomial infections in medical intensive care units in the United States. National Nosocomial Infections Surveillance System. Crit Care Med (En línea) 1999 (citado 21 de noviembre de 2014). 27(5):887-92. URL disponible en: http://www.ncbi.nlm.nih.gov/pubmed/103 62409

15. Bodí M, Garnacho J. Pseudomonas aeruginosa: tratamiento combinado frente a monoterapia. Med Intensiva (En línea).2007 (citado el 21 de noviembre de 2014). 31(2):83-7. URL disponible en: http://scielo.isciii.es/scielo.php?script $=$ sci_ arttext\&pid =S0210-56912007000200005

16. Fernández $S$, Brener $P$, Mariani $G$, Fustiñana C, Marcó del Pont J. Infecciones nosocomiales en una Unidad de Cuidados Neonatales: programa de vigilancia epidemiológica. Arch Argent Pediatría (En línea). 2011 (citado el 21 de noviembre de 2014) 109(5): 398-405. URL disponible en:

http://www.scielo.org.ar/scielo.php?pid=S 0325-

00752011000500005\&script $=$ sci_arttext

17. Arias R. Determinación de los factores de riesgo que influyen en la incidencia de infecciones nosocomiales en el servicio de neonatología del hospital. [Tesis] 2015. Ecuador: Repositorio digital (citado el 28 de agosto de 2018). URL disponible en: http://www.dspace.uce.edu.ec/bitstream/2 5000/6360/1/T-UCE-0008-073.pdf

18. Rodríguez $M$, Duarte $A$, Alfieri $P$, et al. Infecciones Intrahospitalarias en una Unidad de Cuidados Intensivos Pediátricos. Análisis de Tres Años de Vigilancia (20062008) Pediatría (Asunción) [En línea]. (Citado 21 de noviembre de 2014). URL disponible

en:http://scielo.iics.una.py/scielo.php?scri pt $=$ sci_arttext\&pid $=$ S1683$98032010000100003 \&$ Ing $=$ es\&nrm $=$ iso

19. Enfedaque C, Gentile A, Del Valle $H$, Procopio A, Durante A. Impacto de las bacteriemias nosocomiales en una unidad de cuidados intensivos neonatales. Arch Argent Pediatría (En línea).2004, (citado 21 de noviembre de 2014). 102(5):33543. URL disponible en: http://www.scielo.org.ar/scielo.php?script =sci_arttext\&pid=S032500752004000500005

20. Hurtado J, Gudelia R, Rivas R. Infecciones hospitalarias en una unidad de cuidado intensivo neonatal: pasado y presente. Enf Inf Microbiol [En línea] 2013 [Citado el 28 de diciembre de 2018]. 33(3):113-117. URL disponible en: http://www.imbiomed.com.mx/1/1/articulo s.php?method=showDetail\&id_articulo $=95$ 765\&id_seccion $=3543 \&$ id_ejemplar $=9360 \%$ id_revista $=212$

21. Mussi MM, Nascimento SD. Infecções neonatais hospitalares. J Pediatr Rio J. [em línea] 2001 [Citado 21 de noviembre de 2014]. 77(1):81-96. URL Disponible en: http://www.jped.com.br/conteudo/01-77S81/port.pdf

22. Paula $A$, Salge $A$, Palos Prado $M$. Infecciones relacionadas con la asistencia a la salud en unidades de terapia intensiva neonatal: una revisión integradora. [En línea] 2017. (citado el 10 de diciembre de 2018). 16 (1):508-21. URL disponible en: https://doi.org/10.6018/eglobal.16.1.2380 41

23. Organización Mundial de la Salud (OMS). Pruebas que corroboran la importancia de la higiene de las manos [En línea]. WHO. (citado 21 de noviembre de 2014). URL disponible en: http://www.who.int/gpsc/country_work/es /

24. Coelho MS, Silva C, Faria SM. Higiene de manos como estrategia fundamental en el control de infección hospitalaria: un estudio cuantitativo. Enferm Glob [En línea] 2011 [Citado 21 de noviembre de 2014]. 10(21). URL disponible en: http://scielo.isciii.es/scielo.php?pid=S1695 $61412011000100003 \&$ script $=$ sci_arttext\&tl $\mathrm{ng}=\mathrm{es}$

25. Pantoja M. Higiene de manos y riesgo de infecciones. Rev Soc Boli Pediatría. 2010; 49(2):83-4.

26. Zamudio I, Meza A, Martínez Y, Miranda MG, Espinosa JG, Rodríguez R. Estudio multimodal de higiene de manos en un hospital pediátrico de tercer nivel. Bol Méd Hosp Infant México. 2012; 69(5):384-90. 